\title{
Lymphoma incidence, survival and prevalence 2004-2014: sub-type analyses from the UK's Haematological Malignancy Research Network
}

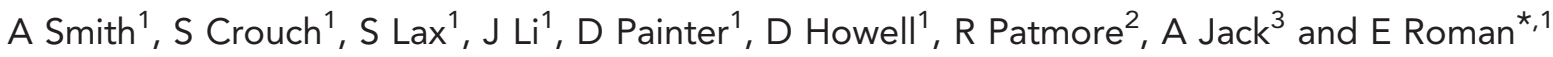 \\ ${ }^{1}$ Epidemiology and Cancer Statistics Group, Department of Health Sciences, University of York, York, YO10 5DD, UK; ${ }^{2}$ Queens \\ Centre for Oncology, Castle Hill Hospital, Hull HU16 5JQ, UK and ${ }^{3}$ St James's Institute of Oncology, Leeds Teaching Hospitals \\ NHS Trust, Leeds LS9 7TF, UK
}

Background: Population-based information about cancer occurrence and survival are required to inform clinical practice and research; but for most lymphomas data are lacking.

Methods: Set within a socio-demographically representative UK population of nearly 4 million, lymphoma data $(N=5796)$ are from an established patient cohort.

Results: Incidence, survival (overall and relative) and prevalence estimates for $>20$ subtypes are presented. With few exceptions, males tended to be diagnosed at younger ages and have significantly $(P<0.05)$ higher incidence rates. Differences were greatest at younger ages: the $<15$ year male/female rate ratio for all subtypes combined being $2.2(95 \% \mathrm{Cl} 1.3-3.4)$. These gender differences impacted on prevalence; most subtype estimates being significantly $(P<0.05)$ higher in males than females. Outcome varied widely by subtype; survival of patients with nodular lymphocyte predominant Hodgkin lymphoma approached that of the general population, whereas less than a third of those with other B-cell (e.g., mantle cell) or T-cell (e.g., peripheral-T) lymphomas survived for $\geq 5$ years. No males/female survival differences were detected.

Conclusions: Major strengths of our study include completeness of ascertainment, world-class diagnostics and generalisability. The marked variations demonstrated confirm the requirement for 'real-world' data to inform aetiological hypotheses, health-care planning and the future monitoring of therapeutic changes.

The lymphomas comprise a heterogeneous group of cancers with diverse aetiologies, treatment pathways and outcomes (Swerdlow et al, 2008; Campo et al, 2011). Critically for research, appreciation of the similarities and differences between the various sub-types only surfaced in recent decades as biological understanding about the relationship between these complex malignancies, the bone marrow, the immune system and the cellular and genetic basis of malignant transformation increased (Harris et al, 2000; Jaffe et al, 2001; Swerdlow et al, 2008; Jaffe, 2009; Campo et al, 2011). Even now, this area of oncology remains one of the most rapidly evolving fields; with developments in genomics, diagnostic technologies and targeted therapies meaning that existing lymphoma definitions are continually subject to change (Puvvada et al, 2013; Dunleavy and Wilson, 2014; O’Connor and Tobinai, 2014).

The pace and recency of scientific advances, coupled with the breadth of laboratory investigations required to make an accurate diagnosis, mean that dependable comprehensive population-based information about the underlying patterns of incidence and survival of clinically meaningful lymphoma subtypes is limited (Morton et al, 2006; Sant et al, 2010, 2014; Marcos-Gragera et al, 2011;

*Correspondence: Professor E Roman; E-mail: eve.roman@york.ac.uk

Received 28 November 2014; revised 6 February 2015; accepted 15 February 2015; published online 24 March 2015 
Smith et al, 2011; Olszewski and Castillo, 2013; Nabhan et al, 2014). Such 'real-world' data are, however, required not only to inform aetiological hypotheses and plan future health-care services, but also to monitor the impact of therapeutic changes in the general patient population. This need is particularly pertinent in fast-moving areas like haematological oncology where treatment protocols are subject to rapid change, and 'gold standard' randomised controlled trials are invariably restricted to specific patient sub-groups; often younger patients with fewer co-morbidities (Rothwell, 2005, 2010; Elting et al, 2006; Janson et al, 2009; Al-Refaie et al, 2011; Freemantle et al, 2013; Van de Water et al, 2014). Furthermore in some countries, particularly those where universal health-care coverage is lacking, the likelihood of trial participation usually varies with socio-economic status, gender and ethnicity (Murthy et al, 2004; Penberthy et al, 2012; Kwiatkowski et al, 2013; Mohd Noor et al, 2013; Unger et al, 2013). Such biases impact on the external validity of experimental treatment trials; and 'real-world' observational data are increasingly being used to provide context and evaluate treatment effectiveness across the whole patient population (Sehn et al, 2005; Armstrong, 2012; Hershman and Wright, 2012; Kodeda et al, 2013; Tripathy et al, 2013; Smith et al, 2014).

In the case of lymphomas, an added dimension is provided by the fact that the pathways of patients diagnosed with incurable but comparatively indolent subtypes, such as follicular lymphoma and marginal zone lymphoma, may begin with a period of 'activemonitoring/watch and wait'. The resulting patient pathways can be complex and diverse, with individual patients differing widely in their need for, and response to, different treatment regimens; some having long periods of observation, and others having multiple courses of chemotherapy (Dreyling et al, 2013, 2014; Michallet et al, 2013). In such a circumstance, extrapolating survival data derived from specific treatment trials to the general patient population is problematic and may result in misleading estimates. In addition, depending on the data feeds used for case ascertainment, the fact that some lymphoma patients are not treated can pose further challenges for cancer registries, and the frequency estimates (incidence and prevalence) they produce.

The UK's population-based Haematological Malignancy Research Network (HMRN) was specifically established in 2004 to address the needs outlined above, by producing 'real-time' generalisable data that would inform contemporary clinical practice and research (Smith et al, 2010). With nearly 4 million people, representing $6 \%$ of the UK population, the socio-demographic composition (age, gender, deprivation) of the regional population mirrors that of the UK as a whole. All diagnoses ( $>2200$ a year) are made and coded by clinical specialists working within a single integrated haematopathology laboratory, irrespective of the patient's age, treatment intent, or management within the National Health Service or private sector (Smith et al, 2011). With its emphasis on completeness and utilisation of primary-source information, HMRN's data are increasingly being used to provide 'gold-standard' information to facilitate decision making (NCIN/ECSG, 2014; NICE, 2014). The present paper reports incidence, survival and prevalence estimates on over 20 lymphoma subtypes traditionally categorised topographically as being either Hodgkin or non-Hodgkin (World Health Organization, 1992). Providing the best available up-to-date population-based information, the lymphomas included were diagnosed over the period 2004-2012 and followed-up through to March 2014.

\section{METHODS}

Data are from the UK's population-based Haematological Malignancy Research Network (www.hmrn.org). Initiated in
2004, full details of its structure, data collection methods and ethical approvals have been previously described (Smith et al, 2010). Briefly, within HMRN, patient care is provided by 14 hospitals organised into five multi-disciplinary teams; and clinical practice adheres to national guidelines. As a matter of policy, all diagnoses are made and coded by clinical specialists at a single integrated haematopathology laboratory-the Haematological Malignancy Diagnostic Service (www.hmds.info); cited in the UK's Department of Health's Cancer Reform Strategy (2007) as 'the model for delivery of complex diagnostic services'. HMRN has Section 251 support under the NHS Act 2006, and all patients have full-treatment, response and outcome data collected to clinical trial standards; all are 'flagged' for death and subsequent cancer registrations at the national Medical Research Information Service (MRIS) and routinely linked to nationwide information on Hospital Episode Statistics.

For analytical purposes, area-based population counts were sourced from the Office National Statistics (Office for National Statistics, 2001). All analyses were conducted either in the statistical package Stata 12 (Stata-Corp, 2011) or R (R Core Team, 2013). Incidence rates and their 95\% confidence intervals (CIs) were estimated by Poisson regression. Directly age-standardised rates (European) were calculated using the Stata command 'dstdize' and corresponding standardised sex rate ratios and their 95\% confidence intervals were estimated (Jensen, 1991). The overall survival was calculated using standard time to event analyses and the program strel (v1.2.7) was used to estimate relative survival; age- and sex-specific background mortality rates were obtained from national life tables (Cancer Research UK, 2006). Prevalence estimates (3, 5 and 10 year) and corresponding confidence intervals were calculated from incidence and survival data using R's 'survival' and 'rms' libraries; 3 and 5 year estimates were calculated directly from the patient cohort, and Monte-Carlo simulation techniques were employed to generate the larger 10-year values (Crouch et al, 2014).

\section{RESULTS}

The 5796 lymphomas diagnosed September 2004 to August 2012 are distributed by sub-type and gender in Table 1; with frequencies and median ages at diagnosis being given for subtypes that had 10 or more diagnoses during the 8-year period. The traditional categories of non-Hodgkin and Hodgkin are shown first, followed by the more meaningful cell-of-origin groupings. Mature B-cell malignancies, which comprise around $94.7 \%(N=5488)$ of the total, occurred far more frequently than the rarer T-cell subtypes $(N=308)$; with diffuse large B-cell lymphoma accounting for around 4 out of 10 lymphoma diagnoses, followed by the more indolent follicular and marginal zone subtypes, which when combined accounted for a further 3 out of 10 lymphoma diagnoses.

As with many other cancers, the likelihood of an individual being diagnosed with lymphoma increases markedly with age, the median age at diagnosis being 67.2 years (interquartile range 54.976.5 years) for all patients combined (Table 1). However, unlike many other cancers, some lymphomas can be diagnosed at any age, with different subtypes dominating at different ages, as can be seen more clearly in Figures 1 and 2: Figure 1 showing the age-specific rates of the main subtypes, and Figure 2 the corresponding distribution within age classes. Hodgkin and Burkitt lymphomas dominate the paediatric age range $(<15$ years), where there were no cases of follicular lymphoma (youngest patient 19 years), marginal zone lymphoma (youngest patient 20 years), or mantle cell lymphoma (youngest patient 39 years) within our population. By contrast, in those aged 60 years or more, diffuse large B-cell, marginal-zone and follicular lymphomas accounted for over $80 \%$ 
Table 1. Lymphoma numbers and median ages (IQR) at diagnosis: Haematological Malignancy Research Network (HMRN) 2004-2012

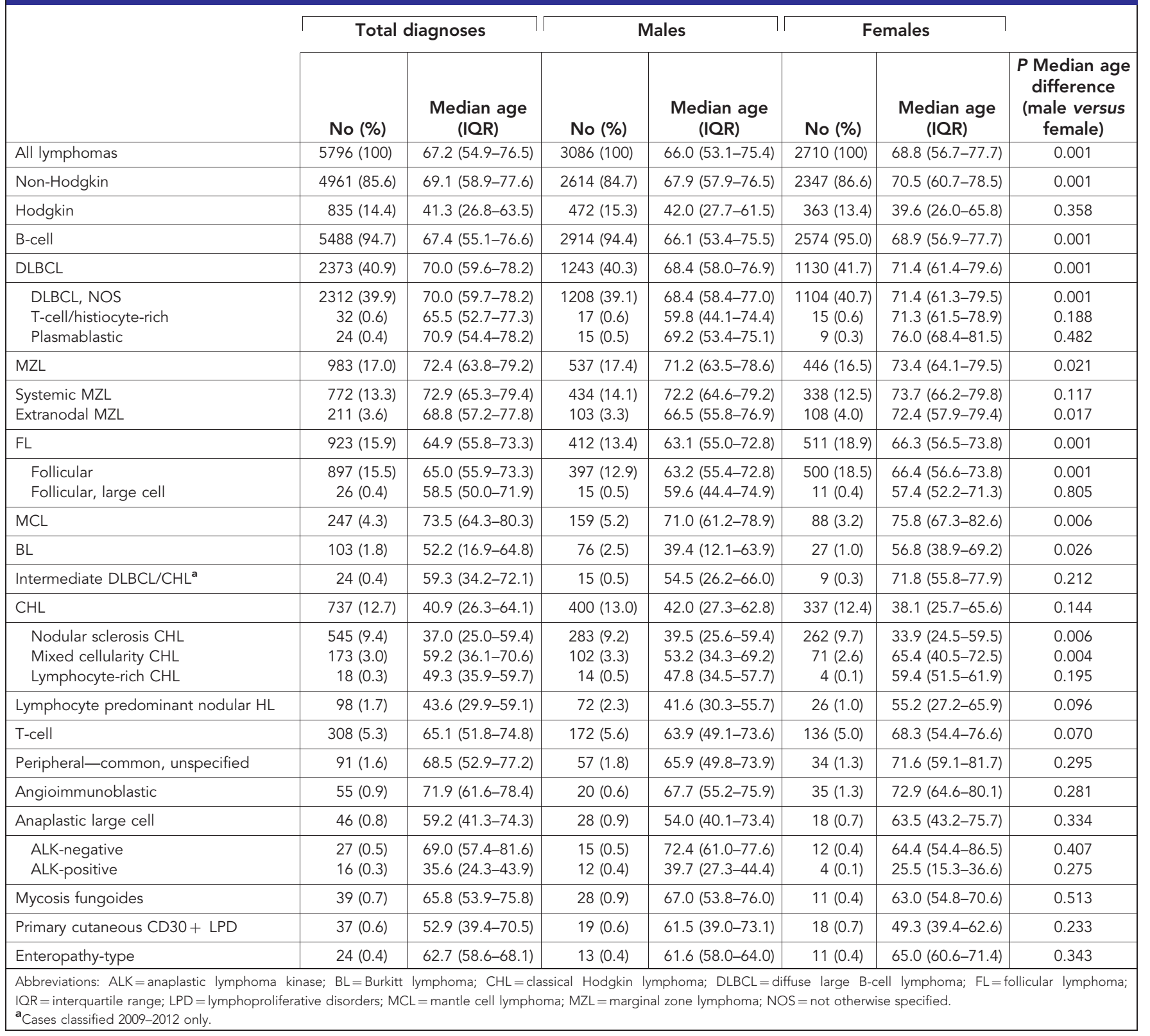

of diagnoses, and the common childhood lymphomas only occurred occasionally. As with B-cell lymphomas, the rarer T-cell lymphomas span the full age range, but again there is considerable heterogeneity by subtype (Table 1): the median age of patients with ALK-positive anaplastic T-cell lymphoma being 35.6 (IQR 24.343.9) and those with angioimmunoblastic T-cell lymphoma being 71.9 years (IQR 61.6-78.4).

In general, males tend to be diagnosed with B-cell lymphomas at younger ages than females (Table 1) and, with one or two exceptions, experience higher rates of disease at all ages; the male/female sex rate ratio (Figure 2) being highest in those diagnosed before the age of 15 years $(2.2 ; 95 \%$ CI $1.3-3.4)$. Indeed, as is evident from Table 2, males are almost three times as likely to develop some B- and T-cell cancer subtypes: the European age standardised sex-rate ratios being 2.57 (95\% CI 2.3-2.88), 2.95 (95\% CI 2.3-3.78), 3.49 (95\% CI 1.53-7.97) and 2.96 (95\% CI 2.28-3.84), respectively, for mantle cell, Burkitt, lymphocyte-rich classical Hodgkin and lymphocyte predominant nodular Hodgkin (B-cell lymphomas); and 2.97 (95\% CI
1.12-7.89) and 2.69 (95\% CI 1.62-4.46), respectively, for ALK-positive anaplastic large cell and mycosis fungoides (T-cell lymphomas).

Amongst the lymphomas, there are marked outcome differences by subtype, as is evident from the 5-year overall and relative survival estimates given in Table 3 and the survival curves shown for the eight main B-cell lymphoma categories in Figure 3. At one extreme, the survival of patients with nodular lymphocyte predominant Hodgkin lymphoma approaches that of the general population (Figure 3); and with no deaths among women in the follow-up period, gender-specific data are not presented in Table 3. By contrast, around three-quarters of patients with mantle cell lymphoma die within 5 years of their diagnosis; the similarity between the overall and relative survival curves confirming that most patients with this cancer die from their disease. With respect to differences between males and females, no statistically significant differences are evident either for overall or relative survival; the sex-specific relative survival estimates, which take account of the fact that women tend to live longer than men, 


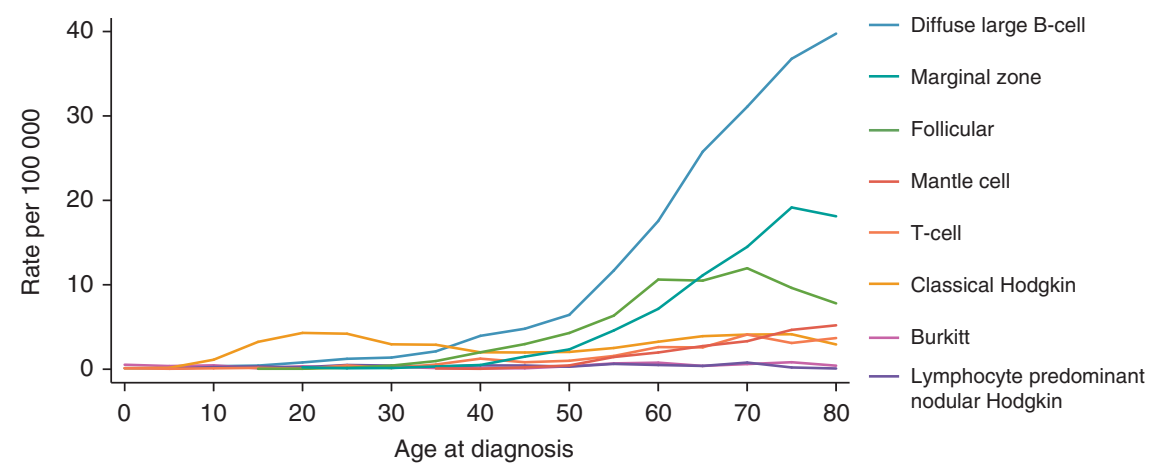

Figure 1. Age-specific rates per 100000 by subtype: Haematological Malignancy Research Network (HMRN) $2004-2012$.

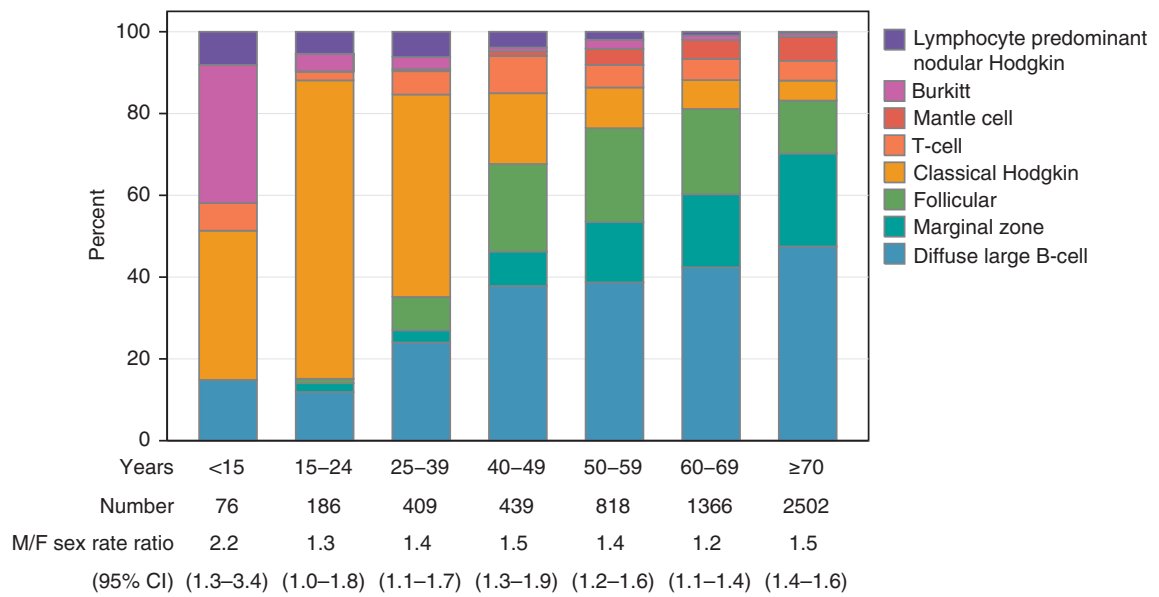

Figure 2. Numbers of cases and sex-rate ratios by sub-type and age: Haematological Malignancy Research Network (HMRN) $2004-2012$.

tending to be more similar to each other than the overall survival estimates (Table 3 ).

Prevalence estimates (3, 5 and 10 year) generated from incidence and survival data are given for the main lymphoma subtypes in Table 4; and the sex-specific estimates of the main B-cell lymphoma subtypes are shown side-by-side in Figure 4. Data for lymphocyte predominant nodular Hodgkin lymphoma are not shown because the numbers of deaths were too few to generate reliable estimates. For all lymphomas combined, prevalence ranged from 48.0 (95\% CI 45.8-50.3) per 100000 population within 3 years of diagnosis, through to 72.5 (95\% CI 69.7-75.3) per 100000 within 5 years and 123.7 (95\% CI 120.0-127.4) within 10 years. For some lymphomas, such as diffuse large B-cell lymphoma where the corresponding 3-, 5- and 10-year point estimates are 17.6, 25.9 and 43.3 per 100000 , respectively, the prevalent pools will contain individuals who have been cured of their cancer; the proportion falling as the time-frame lengthens. On the other hand, for chronic incurable lymphomas like follicular lymphoma where the 3,5 and 10 year estimates are 9.7, 14.8 and 25.2, respectively, the prevalent pools will be comprised of individuals who are either being actively monitored or who are receiving treatment for their disease.

The male to female prevalence differences evident in Table 4 and Figure 4, are largely due to differences in both age at diagnosis and underlying incidence patterns: males tend to be diagnosed at younger ages (Table 1) and have higher disease incidence levels (Table 2). Given these, it is perhaps not surprising that, with the exception of follicular lymphoma, the 3,5 and 10 year prevalence estimates for males tend to be higher than those of females across all main subtypes; resulting in 10-year prevalence estimates for all lymphomas combined of 138.3 (95\% CI 132.7-144.0) and 109.9 (95\% CI 105.1-114.8) per 100000 for males and females respectively-a difference of almost 30 per 100000 . It is also important to note that these differences are not due to differential survival: the 5-year relative survival estimates for all lymphomas combined being 67.2 (95\% CI 65.0-69.2) and 67.8 (95\% CI 65.569.9) respectively (Table 3 ).

\section{DISCUSSION}

This paper presents contemporary sex-specific incidence, prevalence and survival estimates for more than 20 lymphoma subtypes, providing much needed 'real-world' data to better inform practitioners and researchers. To our knowledge, this is the first time that reliable population-based occurrence and survival estimates for several clinically meaningful lymphoma subtypes have been presented side-by-side. The benefits of this are immediately apparent. Within categories that are often lumped together, outcome varied markedly from one subtype to another; patients with some disease subtypes tending to have near normal lifespan, whereas those with others often died rapidly from their disease. Furthermore, strong differences between males and females were observed with respect to subtype incidence and prevalence frequencies, as well as age at cancer onset. Such differences have clear implications not only for aetiological hypotheses and clinical practice, but also for health service planning.

With respect to descriptive patterns, mature B-cell neoplasms dominated our data; the commonest subtype being diffuse large B-cell lymphoma (median diagnostic age 70.0 years), which accounted for $40 \%$ of the total, and the rarest T-cell ALK-positive 


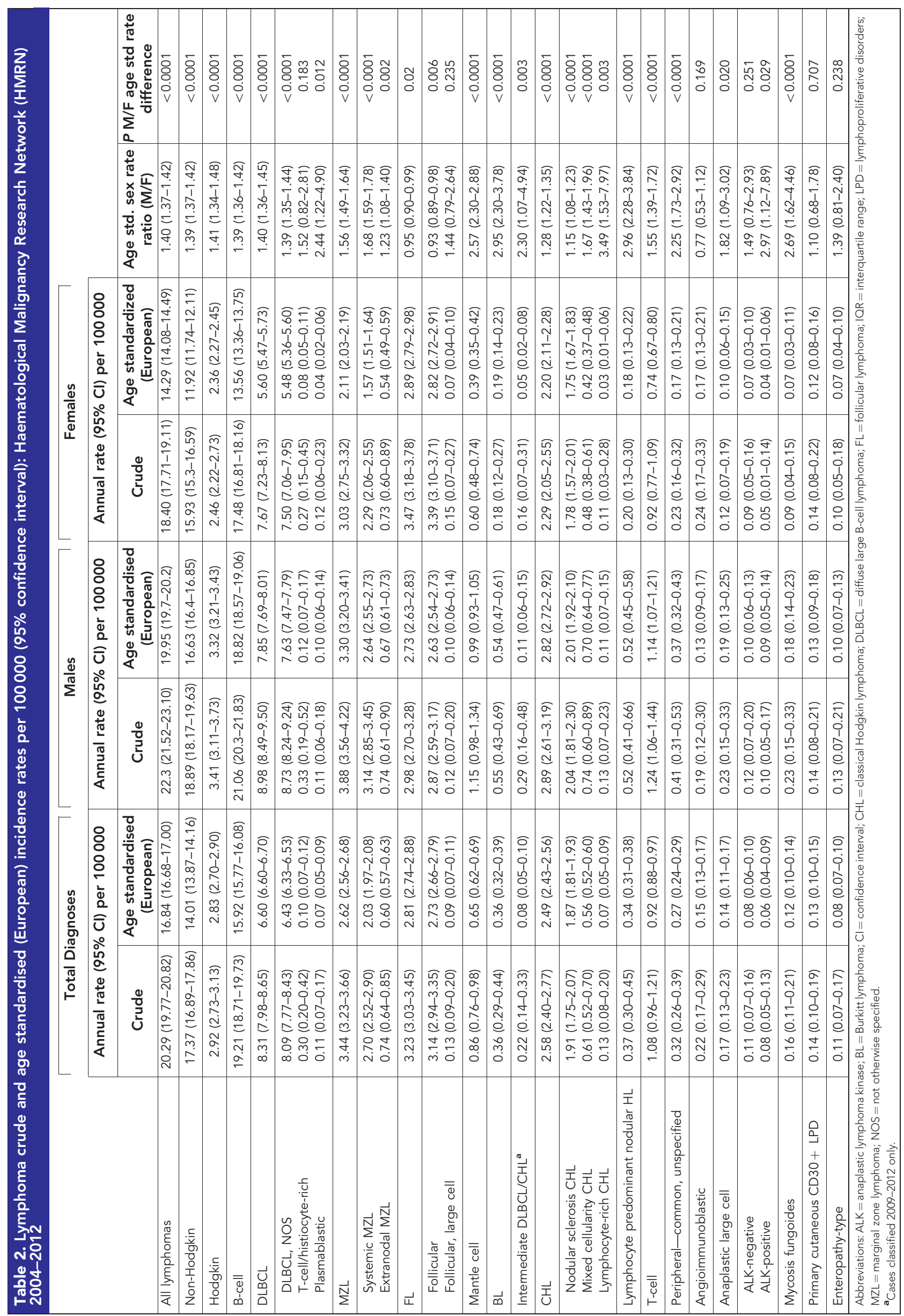


Table 3. Lymphoma 5-year OS and RS estimates (95\% confidence interval): Haematological Malignancy Research Network (HMRN) diagnosed 2004-2012 and followed through to 2014

\begin{tabular}{|c|c|c|c|c|c|c|}
\hline & \multicolumn{2}{|c|}{ Total diagnoses } & \multicolumn{2}{|c|}{ Males } & \multicolumn{2}{|c|}{ Females } \\
\hline & OS $(95 \% \mathrm{Cl})$ & RS $(95 \% \mathrm{Cl})$ & OS $(95 \% \mathrm{Cl})$ & RS (95\% Cl) & OS $(95 \% \mathrm{Cl})$ & RS (95\% Cl) \\
\hline All lymphomas & $57.4(56.0-58.7)$ & $67.4(65.9-68.9)$ & $57.0(55.1-58.8)$ & $67.2(65.0-69.2)$ & $57.8(55.8-59.7)$ & $67.8(65.5-69.9)$ \\
\hline Hodgkin & $78.9(75.8-81.7)$ & $84.9(81.7-87.6)$ & 77 (72.6-80.7) & $82.3(77.7-86.1)$ & $81.5(76.8-85.3)$ & $87.7(82.6-91.4)$ \\
\hline B-cell & $58.4(57-59.8)$ & $68.8(67.2-70.3)$ & $58.0(56.0-59.9)$ & $68.5(66.3-70.6)$ & $58.9(56.8-60.9)$ & $69.1(66.8-71.3)$ \\
\hline DLBCL & $46.3(44.2-48.4)$ & $54.8(52.4-57.1)$ & $46.6(43.6-49.5)$ & $55.5(52.0-58.8)$ & $46.1(43.0-49.1)$ & $54.2(50.7-57.5)$ \\
\hline T-cell/histiocyte-rich & $64.5(45.1-78.5)$ & $67.9(46.8-82.0)$ & $58.0(31.7-77.3)$ & $61.1(32.5-80.5)$ & $71.7(41.1-88.3)$ & $73.4(41.1-89.8)$ \\
\hline Plasmablastic & $16.3(4.8-33.7)$ & $17.2(5.1-35.5)$ & $17.5(3.2-41.1)$ & $18.5(3.4-43.2)$ & $14.5(1.8-39.4)$ & $14.7(1.8-40.0)$ \\
\hline MZL & $61.2(57.7-64.5)$ & $77.2(72.9-80.8)$ & $60.7(55.9-65.1)$ & $77.6(71.5-82.5)$ & $61.9(56.6-66.7)$ & $76.4(69.9-81.7)$ \\
\hline Systemic MZL & $57.4(53.4-61.2)$ & $73.0(68.0-77.4)$ & $58.3(52.9-63.3)$ & $75.3(68.3-80.9)$ & $56.3(50.0-62.1)$ & $70.0(62.1-76.5)$ \\
\hline Extranodal MZL & $74.7(67.7-80.3)$ & $87.9(78.7-93.3)$ & $70.3(59.6-78.7)$ & $83.6(68.5-91.9)$ & $78.8(69.2-85.8)$ & $89.9(75.7-96.0)$ \\
\hline $\mathrm{FL}$ & $75.6(72.4-78.5)$ & $86.5(83.0-89.4)$ & $76.5(71.6-80.7)$ & $86.8(81.2-90.9)$ & $74.9(70.5-78.8)$ & $86.6(81.5-90.4)$ \\
\hline $\mathrm{BL}$ & $51.0(40.9-60.2)$ & $52.9(42.4-62.4)$ & $55.2(43.3-65.6)$ & $57.7(45.1-68.4)$ & $39.2(21.4-56.7)$ & $39.9(21.7-57.6)$ \\
\hline Intermediate DLBCL/CHL ${ }^{a}$ & $83.1(61.0-93.3)$ & $84.0(61.0-94.0)$ & $86.6(56.2-96.5)$ & $87.1(55.7-96.8)$ & 76.0 (33.3-93.4) & $76.8(32.7-94.0)$ \\
\hline Classical Hodgkin (CHL) & $76.5(73.1-79.6)$ & $82.5(78.9-85.5)$ & $73.6(68.7-77.8)$ & $78.7(73.5-83.0)$ & $80.0(75.1-84.1)$ & $86.5(81.0-90.5)$ \\
\hline Nodular sclerosis $\mathrm{CHL}$ & $80.3(76.5-83.5)$ & $86.0(82.0-89.2)$ & $75.7(69.9-80.6)$ & $80.8(74.5-85.7)$ & $85.0(79.9-88.9)$ & $91.5(85.5-95.1)$ \\
\hline Mixed cellularity $\mathrm{CHL}$ & $63.3(55.3-70.3)$ & $69.3(60.3-76.7)$ & $65.2(54.8-73.8)$ & $70.4(58.7-79.3)$ & $60.8(47.7-71.7)$ & $65.3(50.7-76.5)$ \\
\hline T-cell & $39.5(33.7-45.2)$ & $45.4(38.8-51.8)$ & $40.8(33.0-48.5)$ & $46.8(37.8-55.4)$ & $37.8(29.4-46.2)$ & $42.2(32.7-51.4)$ \\
\hline Peripheral-common, unspecified & $17.6(10.3-26.5)$ & $19.7(11.5-29.5)$ & $20.9(11.1-32.9)$ & $23.2(12.2-36.3)$ & $11.7(3.5-25.3)$ & $12.6(3.7-27.1)$ \\
\hline Angioimmunoblastic & $24.2(12.5-37.9)$ & $26.2(13.5-40.9)$ & $29.5(10.3-51.9)$ & $31.0(10.7-54.1)$ & $23.2(9.9-39.7)$ & $24.8(10.5-42.2)$ \\
\hline Anaplastic large cell & $46.5(30.5-60.9)$ & $50.8(33.0-66.2)$ & $40.7(20.8-59.8)$ & $43.7(21.9-63.7)$ & $55.1(30.1-74.4)$ & $57.4(30.8-77.0)$ \\
\hline ALK-negative & $17.6(10.3-26.5)$ & $19.7(11.5-29.5)$ & $21.5(3.8-48.6)$ & $23.1(3.9-51.7)$ & $32.8(10.2-58.0)$ & $34.2(10.4-60.1)$ \\
\hline
\end{tabular}

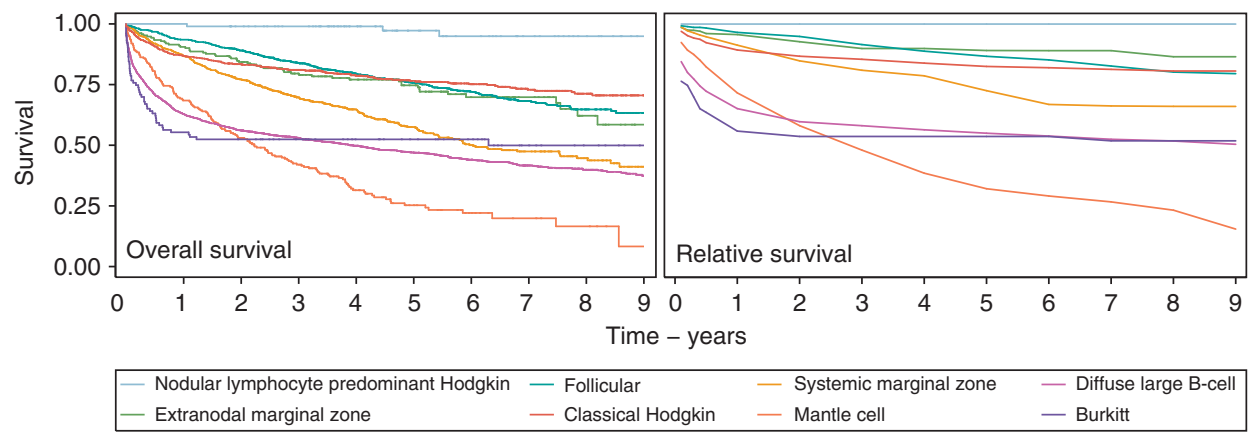

Figure 3. Overall and relative survival by subtype: Haematological Malignancy Research Network (HMRN) 2004-2012.

anaplastic large cell lymphoma (median diagnostic age 35.6 years) which accounted for only $0.3 \%$. Striking differences between males and females in relation to their levels of disease occurrence and ages at diagnosis were observed: males consistently tending to have significantly higher age-standardised incidence rates and to be diagnosed at younger ages, resulting in a doubling of the male/ female rate ratio for all lymphomas combined in those diagnosed before 15 years of age. Such strong gender differences have a big impact on prevalence; the combined lymphoma 10 -year prevalence estimate in our dataset being 30 per 100000 higher in males than in females. That haematological malignancies often occur more frequently in males than females has been noted by others (Morton et al, 2006); and in this regard subtypes that fail to exhibit these incidence/age features stand out; follicular lymphoma being the only mature B-cell lymphoma to occur significantly more frequently in women than men and nodular sclerosis classical Hodgkin lymphoma being the only one with a significantly younger diagnostic age in females than males. Likewise, nearly all 
Table 4. Lymphoma 3, 5 and 10 year prevalence estimates ( $95 \%$ confidence interval) per 100,000: Haematological Malignancy Research Network (HMRN) 2004-2012

\begin{tabular}{|c|c|c|c|c|c|c|c|c|c|}
\hline & \multicolumn{9}{|c|}{ Prevalence proportion per 100000} \\
\hline & \multicolumn{3}{|c|}{ Total diagnoses } & \multicolumn{3}{|c|}{ Males } & \multicolumn{3}{|c|}{ Females } \\
\hline & 3-year & 5-year & 10-year & 3-year & 5-year & 10-year & 3-year & 5-year & 10-year \\
\hline All lymphomas & $48.0(45.8-50.3)$ & $72.5(69.7-75.3)$ & $123.7(120.0-127.4)$ & $53.6(50.1-57.0)$ & $81.0(76.7-85.2)$ & $138.3(132.7-144.0)$ & $42.8(39.8-45.8)$ & $64.5(60.9-68.2)$ & $109.9(105.1-114.8)$ \\
\hline Non-Hodgkin & $39.9(37.9-42.0)$ & $59.9(57.4-62.5)$ & $100.1(96.7-103.4)$ & $43.6(40.5-46.7)$ & $65.5(61.7-69.3)$ & $109.7(104.7-114.8)$ & $36.5(33.7-39.3)$ & $54.7(51.3-58.1)$ & $91.0(86.6-95.4)$ \\
\hline Hodgkin & $8.3(7.3-9.2)$ & $12.9(11.7-14.0)$ & $24.0(22.4-25.6)$ & $10.1(8.6-11.6)$ & $15.7(13.9-17.6)$ & $28.8(26.3-31.3)$ & $6.6(5.4-7.7)$ & $10.2(8.7-11.6)$ & $19.4(17.4-21.4)$ \\
\hline B-cell & $46.2(44.0-48.5)$ & $69.9(67.2-72.6)$ & $119.5(115.9-123.2)$ & $51.4(48.1-54.8)$ & 77.7 (73.6-81.9) & $133.1(127.6-138.7)$ & $41.3(38.4-44.3)$ & $62.5(58.9-66.1)$ & $106.8(102.0-111.6)$ \\
\hline Diffuse large B-cell & $17.6(16.2-18.9)$ & $25.9(24.2-27.5)$ & $43.3(41.1-45.5)$ & $20.0(17.9-22.1)$ & $28.8(26.3-31.4)$ & $47.9(44.5-51.2)$ & $15.3(13.5-17.0)$ & $23.1(20.9-25.3)$ & $39.0(36.1-41.9)$ \\
\hline Marginal Zone & $10.1(9.0-11.1)$ & $15.2(13.9-16.5)$ & $23.8(22.2-25.4)$ & $11.2(9.6-12.8)$ & $17.1(15.1-19.0)$ & $26.7(24.2-29.2)$ & $9.0(7.6-10.4)$ & 13.5 (11.8-15.1) & $21.1(18.9-23.2)$ \\
\hline Follicular & $9.7(8.7-10.7)$ & $14.8(13.6-16.1)$ & $25.2(23.5-26.9)$ & $8.6(7.2-10.0)$ & $13.6(11.9-15.4)$ & $24.1(21.8-26.5)$ & $10.7(9.2-12.2)$ & $16.0(14.1-17.8)$ & $26.2(23.8-28.6)$ \\
\hline Mantle cell & $1.8(1.3-2.2)$ & $2.4(1.9-2.9)$ & $3.3(2.7-4.0)$ & $2.3(1.6-3.0)$ & $3.4(2.5-4.2)$ & $4.7(3.7-5.8)$ & $1.2(0.7-1.8)$ & $1.5(1.0-2.1)$ & $2.0(1.4-2.7)$ \\
\hline Burkitt & $0.6(0.4-0.9)$ & $1.0(0.7-1.4)$ & $1.8(1.4-2.3)$ & $1.0(0.5-1.4)$ & $1.6(1.0-2.1)$ & $3.0(2.1-3.8)$ & $0.3(0.0-0.5)$ & $0.5(0.2-0.9)$ & $0.8(0.4-1.2)$ \\
\hline Classical Hodgkin & $6.9(6.1-7.8)$ & $11.0(9.9-12.1)$ & $20.4(18.9-21.9)$ & $7.9(6.5-9.2)$ & $12.8(11.1-14.5)$ & $23.2(20.9-25.5)$ & $6.1(5.0-7.2)$ & $9.3(7.9-10.7)$ & $17.8(15.9-19.8)$ \\
\hline T-cell & $1.8(1.4-2.2)$ & $2.6(2.1-3.2)$ & $4.3(3.6-5.0)$ & $2.1(1.4-2.8)$ & $3.2(2.4-4.1)$ & $5.2(4.1-6.3)$ & $1.5(0.9-2.0)$ & $2.1(1.4-2.7)$ & $3.4(2.6-4.3)$ \\
\hline
\end{tabular}

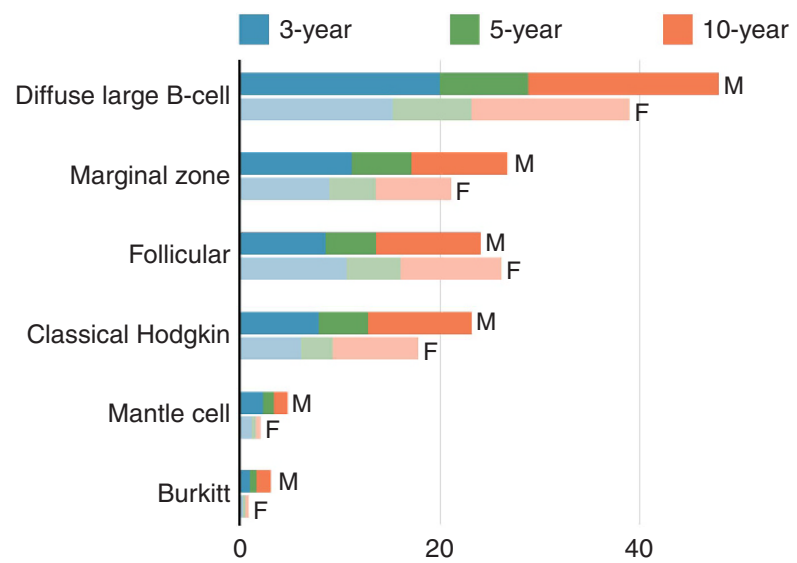

Prevalence per 100000

Figure 4. Mature B-cell lymphoma 3, 5, and 10 year prevalence estimates by subtype: Haematological Malignancy Research Network (HMRN) 2004-2012.

T-cell lymphomas occurred at significantly higher levels in males than in females; however, no statistically significant differences between males and females with respect to age at diagnosis were observed. Unfortunately, ethnic differences could not be examined for in the dataset as $95 \%$ of the population are Caucasian.

In contrast to the pronounced gender differences seen for lymphoma occurrence and age at diagnosis, no statistically significant survival differences between males and females were detected-either overall or within any of the subtypes. This result is in broad agreement with cancer registry findings from EUROCARE-4, where close agreement between male and female relative survival estimates in those diagnosed 2000-2002 was also noted (Marcos-Gragera et al, 2011). Given the incorporation of male sex into the Hasenclever prognostic score (Hasenclever and Diehl, 1998), it is perhaps worth noting the borderline nature of the overall and relative survival differences for the classical Hodgkin lymphomas. For nodular sclerosis classical Hodgkin lymphoma, the 5-year overall survival estimates for males and females were 75.7 (95\% CI 69.9-80.6) and 85.0 (95\% CI 79.9-88.9) respectively, and the 5-year relative survival estimates were slightly closer at 80.8 (95\% CI 74.5-85.7) and 91.5 (95\% CI 85.5-95.1) respectively. Interestingly, mixed cellularity classical Hodgkin lymphoma shows a slight, but again not statistically significant, bias in the other direction, the 5-year relative survival estimates being 70.4 (95\% CI 58.7-79.3) and 65.3 (95\% CI 50.7-76.5) respectively. When making such comparisons, it is important to recall that most international prognostic scores are developed using data either from trials or from selected groups of treated patients (International Non-Hodgkin's Lymphoma Prognostic Factors Project, 1993; Hasenclever and Diehl, 1998; Solal-Céligny et al, 2004). In the case of Hodgkin lymphoma, the Hasenclever was based on patients aged 15-65 years who were treated for advanced Hodgkin lymphoma with curative intent before 1992, and for whom outcome was known (Hasenclever and Diehl, 1998).

Taken as whole, survival was generally better for B-cell lymphomas than for T-cell lymphomas, the corresponding 5-year relative survival estimates being 68.8\% (95\% CI 67.2-70.3) and $45.4 \%$ (38.8-51.8) respectively. However, both groups contain a mix of comparatively indolent and aggressive disease forms, some of which are curable and others of which are not. B-cell lymphomas like follicular lymphoma and marginal zone, as well as certain T-cell lymphomas like mycosis fungoides, often follow a remitting/relapsing course that can include long periods without treatment. Reflective of this pattern, the 5-year survival of patients with these comparatively indolent, but currently incurable, subtypes ranges between 75 and $90 \%$. Wider survival variations were, however, evident among the more aggressive lymphomas, several of which tend to be treated with intensive first-line chemotherapy regimens. In this regard, treatment for most of the Hodgkin lymphomas was clearly extremely effective, with 5-year relative survival estimates in excess of $80 \%$. For other potentially curable subtypes, like diffuse large B-cell and Burkitt's, most deaths occurred within the first year; and although the 5-year relative survival was only $50 \%$, the flattening of the curve after this point implies that the mortality of patients who survive treatment is similar to that of the general population. Currently, outcomes seem less promising for other rarer lymphomas; including mantle cell where the 5-year relative survival of around $30 \%$ continued to fall across our 9 years of follow-up, as well as many of the T-cell lymphomas where the common peripheral T-cell and ALK-negative anaplastic large cell both had 5-year relative survival estimates below $20 \%$.

Major strengths of our study include its large well-defined catchment area, completeness of ascertainment and world-class diagnostics. With respect to the latter, all lymphomas were diagnosed and coded using the latest WHO oncology classification by clinical specialists working at a single fully integrated laboratory-the Haematological Malignancy Diagnostic Service (HMDS). As one of the largest integrated haematopathology laboratories in Europe, HMDS has a strong record of national/ international leadership in research in lymphoid malignancies, and is cited by the UK's National Institute for Health and Care 
Table 5. Comparison between the age-standardised (European) incidence and prevalence point-estimates for non-Hodgkin and Hodgkin lymphomas derived in this paper from the Haematological Malignancy Research Network (HMRN) and by the International Agency for Research on Cancer's European Union (EUCAN) estimates (http://eco.iarc.fr/eucan/)

\begin{tabular}{|c|c|c|c|c|c|c|c|c|c|}
\hline & \multicolumn{3}{|c|}{ Incidence } & \multicolumn{6}{|c|}{ Prevalence } \\
\hline & \multirow[b]{2}{*}{ Total } & \multirow[b]{2}{*}{ Males } & \multirow[b]{2}{*}{ Females } & \multicolumn{3}{|c|}{ 3-year } & \multicolumn{3}{|c|}{ 5-year } \\
\hline & & & & Total & Males & Females & Total & Males & Females \\
\hline \multicolumn{10}{|c|}{ Non-Hodgkin } \\
\hline HMRN & 14.0 & 16.6 & 11.9 & 39.9 & 43.6 & 36.5 & 59.9 & 65.5 & 54.7 \\
\hline EUCAN & 14.2 & 16.8 & 12.0 & 39.4 & 44.5 & 34.5 & 58.6 & 66.4 & 51.2 \\
\hline \multicolumn{10}{|c|}{ Hodgkin } \\
\hline HMRN & 2.8 & 3.3 & 2.4 & 8.3 & 10.1 & 6.6 & 12.9 & 15.7 & 10.2 \\
\hline EUCAN & 2.5 & 3.0 & 2.1 & 7.0 & 8.4 & 5.7 & 11.2 & 13.4 & 9.1 \\
\hline
\end{tabular}

Excellence (NICE) guidance as the model for service delivery (Department of Health, 2007, 2011). This means that, as well as having comprehensive accurate data, our patient cohort does not suffer from the data quality issues commonly faced by nonspecialist population-based cancer registries (Sant et al, 2010, 2014). Hence, as can be seen from Table 5, although our incidence and prevalence estimates for the traditional groupings of nonHodgkin lymphoma and Hodgkin lymphoma are reassuringly similar to those calculated for the UK as a whole by the International Agency for Research on Cancer's EUCAN project (http://eco.iarc.fr/eucan/) (Ferlay et al, 2013; Steliarova-Foucher et al, 2014), our B-cell and T-cell age standardised (European) subtype incidence rates tend to be uniformly higher than those estimated by non-specialist European cancer registries (Sant et al, 2010). This disparity is partly due to the fact that the range and depth of data used to make the actual diagnosis are difficult for many cancer registries to access systematically (Marcos-Gragera et al, 2011), and so lymphomas are often registered using not otherwise specified codes, such as lymphoma not otherwise specified (9590) or non-Hodgkin lymphoma not otherwise specified (9591) (Fritz, 2000). Similar not otherwise specified levels for haematological cancers occur within SEER (Surveillance, Epidemiology, and End Results, http://seer.cancer.gov/) registries (Morton et al, 2006), where the use of a different standard population (US 2000 census) adds to the difficulty of making comparisons with European populations (Morton et al, 2006; Li et al, 2015). The US 2000 standard has an older age distribution than the European Standard, so its use results in a general increase; our age-standardised rates (both sexes combined) for diffuse large B-cell and marginal zone lymphomas, for example, increasing from 6.6 and 2.6 per 100000 (European 2013) to 7.0 and 2.8 per 100000 (US 2000), respectively.

In addition to affecting measures of disease occurrence, lack of diagnostic specificity at the point of cancer registration also impacts on survival estimates, where external validity may be further reduced by the data exclusions that are frequently applied (Li et al, 2014). It is not uncommon, for example, to exclude patients when the date of diagnosis falls on the date of death; this being a marker for registrations based on death certificates only (Rachet et al, 2008). In our data, 140 (6.1\%) of the 2300 deaths that occurred within 5 years of diagnosis happened on the day of diagnosis, and clearly omission of such deaths would have led to biased estimates. The 5-year relative survival estimates for diffuse large B-cell lymphoma would, for example, have increased by around 3\% from 54.8 (95\% CI 52.4-57.1) to 57.6 (95\% CI 55.1-60.0) had the 101 deaths that occurred on the day of diagnosis been excluded. Comparisons with clinical trials, which by design usually focus on treated patients in specific subgroups, are equally challenging. Hence, in the general patient population, survival estimates for the more aggressive lymphomas like diffuse large B-cell will tend to be lower than those observed in phase III randomised controlled trials (Cunningham et al, 2013); whereas those for the more indolent lymphomas like follicular, which may be actively monitored rather than treated with chemotherapy, will tend to be higher (Press et al, 2013).

In summary, our contemporary population-based analyses of incidence, prevalence and survival of lymphomas categorised by WHO subtype provides valuable information for researchers, clinicians and patients. Marked variations by subtype, age and sex were demonstrated; confirming that 'real-world' data are required not only to better inform aetiological hypotheses and plan future health-care services, but also to monitor the impact of therapeutic changes at the population level.

\section{ACKNOWLEDGEMENTS}

The Haematological Malignancy Research Network is funded by Leukaemia \& Lymphoma Research (LLR). It has ethics approval (REC 04/01/1205/69) from Leeds West Research Ethics Committee, R\&D approval from each NHS Trust in the study area and exemption from Section 251 of the Health \& Social Care Act (PIAG 1-05(h)/2007).

\section{CONFLICT OF INTEREST}

The authors declare no conflict of interest.

\section{REFERENCES}

Al-Refaie WB, Vickers SM, Zhong W, Parsons H, Rothenberger D, Habermann EB (2011) Cancer trials versus the real world in the United States. Ann Surg. 254: 438-442.

Armstrong K (2012) Methods in comparative effectiveness research. J Clin Oncol Off J Am Soc Clin Oncol 30: 4208-4214.

Campo E, Swerdlow SH, Harris NL, Pileri S, Stein H, Jaffe ES (2011) The 2008 WHO classification of lymphoid neoplasms and beyond: evolving concepts and practical applications. Blood 117: 5019-5032.

Cancer Research UK (2006) Cancer Survival Group. Strel (v.1.2.7) computer program and life tables for cancer survival analysis.

Crouch S, Smith A, Painter D, Li J, Roman E (2014) Determining disease prevalence from incidence and survival using simulation techniques. Cancer Epidemiol 38: 193-199.

Cunningham D, Hawkes EA, Jack A, Qian W, Smith P, Mouncey P, Pocock C, Ardeshna KM, Radford JA, McMillan A, Davies J, Turner D, Kruger A, Johnson P, Gambell J, Linch D (2013) Rituximab plus cyclophosphamide, doxorubicin, vincristine, and prednisolone in patients with newly diagnosed diffuse large B-cell non-Hodgkin lymphoma: a phase 3 comparison of dose intensification with 14-day versus 21-day cycles. Lancet 381: 1817-1826.

Department of Health (2007) Cancer Reform Strategy. 
Department of Health (2011) Improving Outcomes: a Strategy for Cancer.

Dreyling M, Ghielmini M, Marcus R, Salles G, Vitolo U, Ladetto M (2014) Newly diagnosed and relapsed follicular lymphoma: ESMO Clinical Practice Guidelines for diagnosis, treatment and follow-up. Ann Oncol 25(Suppl 3): iii76-iii82.

Dreyling M, Thieblemont C, Gallamini A, Arcaini L, Campo E, Hermine O, Kluin-Nelemans JC, Ladetto M, Le Gouill S, Iannitto E, Pileri S, Rodriguez J, Schmitz N, Wotherspoon A, Zinzani P, Zucca E (2013) ESMO Consensus conferences: guidelines on malignant lymphoma. part 2: marginal zone lymphoma, mantle cell lymphoma, peripheral T-cell lymphoma. Ann Oncol 24: 857-877.

Dunleavy K, Wilson WH (2014) Appropriate management of molecular subtypes of diffuse large B-cell lymphoma. Oncol Williston Park N 28: 326-334.

Elting LS, Cooksley C, Bekele BN, Frumovitz M, Avritscher EBC, Sun C, Bodurka DC (2006) Generalizability of cancer clinical trial results: prognostic differences between participants and nonparticipants. Cancer 106: $2452-2458$.

Ferlay J, Steliarova-Foucher E, Lortet-Tieulent J, Rosso S, Coebergh JWW, Comber H, Forman D, Bray F (2013) Cancer incidence and mortality patterns in Europe: estimates for 40 countries in 2012. Eur J Cancer 49: 1374-1403.

Freemantle N, Marston L, Walters K, Wood J, Reynolds MR, Petersen I (2013) Making inferences on treatment effects from real world data: propensity scores, confounding by indication, and other perils for the unwary in observational research. BMJ 347: f6409.

Fritz A (2000) International classification of diseases for oncology: ICD-O. World Health Organization: Geneva.

Harris NL, Jaffe ES, Diebold J, Flandrin G, Muller-Hermelink HK, Vardiman J (2000) Lymphoma classification-from controversy to consensus: the R.E.A.L. and WHO Classification of lymphoid neoplasms. Ann Oncol 11(Suppl 1): 3-10.

Hasenclever D, Diehl V (1998) A prognostic score for advanced Hodgkin's disease. International Prognostic Factors Project on Advanced Hodgkin's Disease. N Engl J Med 339: 1506-1514.

Hershman DL, Wright JD (2012) Comparative effectiveness research in oncology methodology: observational data. J Clin Oncol. 30: 4215-4222.

International Non-Hodgkin's Lymphoma Prognostic Factors Project (1993) A predictive model for aggressive non-Hodgkin's lymphoma. $N$ Engl J Med. 329: $987-994$.

Jaffe ES (2009) The 2008 WHO classification of lymphomas: implications for clinical practice and translational research. Hematology Am Soc Hematol Educ Program 523-531.

Jaffe ES, Harris Nancy Lee, Stein Harald, Vardiman James (2001) Pathology and genetics of tumours of haematopoietic and lymphoid tissues. Oxford: IARC Press; Oxford University Press (distributor): Lyon.

Janson M, Edlund G, Kressner U, Lindholm E, Påhlman L, Skullman S, Anderberg B, Haglind E (2009) Analysis of patient selection and external validity in the Swedish contribution to the COLOR trial. Surg Endosc. 23: 1764-1769.

Jensen OM (1991) Cancer Registration: Principles and Methods. IARC.

Kodeda K, Nathanaelsson L, Jung B, Olsson H, Jestin P, Sjövall A, Glimelius B, Påhlman L, Syk I (2013) Population-based data from the Swedish Colon Cancer Registry. Br J Surg. 100: 1100-1107.

Kwiatkowski K, Coe K, Bailar JC, Swanson GM (2013) Inclusion of minorities and women in cancer clinical trials, a decade later: Have we improved? Cancer 119: 2956-2963.

Li R, Abela L, Moore J, Woods LM, Nur U, Rachet B, Allemani C, Coleman MP (2014) Control of data quality for population-based cancer survival analysis. Cancer Epidemiol 38: 314-320.

Li Y, Wang Y, Wang Z, Yi D, Ma S (2015) Racial differences in three major NHL subtypes: Descriptive epidemiology. Cancer Epidemiol 39: 8-13.

Marcos-Gragera R, Allemani C, Tereanu C, De Angelis R, Capocaccia R, Maynadie M, Luminari S, Ferretti S, Johannesen TB, Sankila R, KarjalainenLindsberg M-L, Simonetti A, Martos MC, Raphaël M, Giraldo P, Sant M (2011) Survival of European patients diagnosed with lymphoid neoplasms in 2000-2002: results of the HAEMACARE project. Haematologica 96: 720-728.

Michallet A-SA, Lebras LL, Bauwens DD, Bouafia-Sauvy FF, Berger FF, Tychyj-Pinel CC, D'Hombres AA, Salles GG, Coiffier BB (2013) Early stage follicular lymphoma: what is the clinical impact of the first-line treatment strategy? J Hematol Oncol 6: 45.

Mohd Noor A, Sarker D, Vizor S, McLennan B, Hunter S, Suder A, Moller H, Spicer JF, Papa S (2013) Effect of patient socioeconomic status on access to early-phase cancer trials. J Clin Oncol 31: 224-230.
Morton LM, Wang SS, Devesa SS, Hartge P, Weisenburger DD, Linet MS (2006) Lymphoma incidence patterns by WHO subtype in the United States, 1992-2001. Blood 107: 265-276.

Murthy VH, Krumholz HM, Gross CP (2004) Participation in cancer clinical trials: race-, sex-, and age-based disparities. JAMA 291: 2720-2726.

Nabhan C, Aschebrook-Kilfoy B, BC-H Chiu, Kruczek K, Smith SM, Evens AM (2014) The impact of race, age, and sex in Follicular Lymphoma: A comprehensive SEER analysis across consecutive treatment eras. Am J Hematol. 89: 633-638.

NCIN/ECSG (2014) Registration for Blood Cancers in England: comparison of routine data with a specialist population-based register. Available at http://www.ncin.org.uk/cancer_type_and_topic_specific_work/cancer_ type_specific_work/haematological_cancers/ (accessed 10/10/2014).

NICE (2014) Non-Hodgkin's lymphoma: Guidance and guidelines. Available at http://www.nice.org.uk/guidance/indevelopment/ gid-cgwave0671 (accessed 10/10/2014).

O'Connor OA, Tobinai K (2014) Putting the clinical and biological heterogeneity of non-hodgkin lymphoma into context. Clin Cancer Res 20: 5173-5181.

Office for National Statistics (2001) Census: Standard Area Statistics (England) (ESRC/JISC Census programme cnsus dissemination unit, University of Manchester).

Olszewski AJ, Castillo JJ (2013) Survival of patients with marginal zone lymphoma: analysis of the Surveillance, Epidemiology, and End Results database. Cancer 119: 629-638.

Penberthy L, Brown R, Wilson-Genderson M, Dahman B, Ginder G, Siminoff LA (2012) Barriers to therapeutic clinical trials enrollment: differences between African-American and white cancer patients identified at the time of eligibility assessment. Clin Trials 9: 788-797.

Press OW, Unger JM, Rimsza LM, Friedberg JW, LeBlanc M, Czuczman MS, Kaminski M, Braziel RM, Spier C, Gopal AK, Maloney DG, Cheson BD, Dakhil SR, Miller TP, Fisher RI (2013) A comparative analysis of prognostic factor models for follicular lymphoma based on a phase III trial of CHOP-rituximab versus CHOP + 131Iodine-tositumomab. Clin Cancer Res. 19: 6624-6632.

Puvvada S, Kendrick S, Rimsza L (2013) Molecular classification, pathway addiction, and therapeutic targeting in diffuse large B cell lymphoma. Cancer Genet 206: 257-265.

Rachet B, Woods LM, Mitry E, Riga M, Cooper N, Quinn MJ, Steward J, Brenner H, Estève J, Sullivan R, Coleman MP (2008) Cancer survival in England and Wales at the end of the 20th century. Br J Cancer 99(Suppl 1): S2-S10.

R Core Team (2013) A language and environment for statistical computing. Vienna, Austria.

Rothwell PM (2005) External validity of randomised controlled trials: 'to whom do the results of this trial apply?' Lancet 365: 82-93.

Rothwell PM (2010) Commentary: External validity of results of randomized trials: disentangling a complex concept. Int J Epidemiol 39: 94-96.

Sant M, Allemani C, Tereanu C, De Angelis R, Capocaccia R, Visser O, Marcos-Gragera R, Maynadié M, Simonetti A, Lutz J-M, Berrino F (2010) Incidence of hematologic malignancies in Europe by morphologic subtype: results of the HAEMACARE project. Blood 116: 3724-3734.

Sant M, Minicozzi P, Mounier M, Anderson LA, Brenner H, Holleczek B, Marcos-Gragera R, Maynadié M, Monnereau A, Osca-Gelis G, Visser O, De Angelis R. the EUROCARE-5 Working Group (2014) Survival for haematological malignancies in Europe between 1997 and 2008 by region and age: results of EUROCARE-5, a population-based study. Lancet Oncol 15: 931-942.

Sehn LH, Donaldson J, Chhanabhai M, Fitzgerald C, Gill K, Klasa R, MacPherson N, O'Reilly S, Spinelli JJ, Sutherland J, Wilson KS, Gascoyne RD, Connors JM (2005) Introduction of combined CHOP plus rituximab therapy dramatically improved outcome of diffuse large B-cell lymphoma in British Columbia. J Clin Oncol 23: 5027-5033.

Smith AG, Painter D, Howell DA, Evans P, Smith G, Patmore R, Jack A, Roman E (2014) Determinants of survival in patients with chronic myeloid leukaemia treated in the new era of oral therapy: findings from a UK population-based patient cohort. BMJ Open 4: e004266.

Smith A, Howell D, Patmore R, Jack A, Roman E (2011) Incidence of haematological malignancy by sub-type: a report from the Haematological Malignancy Research Network. Br J Cancer 105: 1684-1692.

Smith A, Roman E, Howell D, Jones R, Patmore R, Jack A (2010) The Haematological Malignancy Research Network (HMRN): a new information strategy for population based epidemiology and health service research. Br J Haematol. 148: 739-753. 
Solal-Céligny P, Roy P, Colombat P, White J, Armitage JO, Arranz-Saez R, $\mathrm{Au}$ WY, Bellei M, Brice P, Caballero D, Coiffier B, Conde-Garcia E, Doyen C, Federico M, Fisher RI, Garcia-Conde JF, Guglielmi C, Hagenbeek A, Haïoun C, LeBlanc M, Lister AT, Lopez-Guillermo A, McLaughlin P, Milpied N, Morel P, Mounier N, Proctor SJ, Rohatiner A, Smith P, Soubeyran P, Tilly H, Vitolo U, Zinzani P-L, Zucca E, Montserrat E (2004) Follicular lymphoma international prognostic index. Blood 104: 1258-1265.

Stata-Corp (2011) Stata Statistical Software: Release 12. Stata-Corp, College Station: TX, USA.

Steliarova-Foucher E, O’Callaghan M, Ferlay J, Masuyer E, Rosso S, Forman D, Bray F, Comber H (2014) The European Cancer Observatory: A new data resource. Eur J Cancer. e-pub ahead of print 22 February 2014; doi:10.1016/j.ejca.2014.01.027.

Swerdlow SH, Campo E, Harris NL, Jaffe ES, Pileri SA, Stein H, Thiele J, Vardiman JW (2008) WHO Classification of Tumours of Haematopoietic and Lymphoid Tissues. 4th edn. IARC: Lyon.

Tripathy D, Kaufman PA, Brufsky AM, Mayer M, Yood MU, Yoo B, Quah C, Yardley D, Rugo HS (2013) First-line treatment patterns and clinical outcomes in patients with HER2-positive and hormone receptor-positive metastatic breast cancer from registHER. Oncologist 18: $501-510$.

Unger JM, Hershman DL, Albain KS, Moinpour CM, Petersen JA, Burg K, Crowley JJ (2013) Patient income level and cancer clinical trial participation. J Clin Oncol 31: 536-542.

Van de Water W, Kiderlen M, Bastiaannet E, Siesling S, Westendorp RGJ, van de Velde CJH, Nortier JWR, Seynaeve C, de Craen AJM, Liefers G-J (2014) External validity of a trial comprised of elderly patients with hormone receptor-positive breast cancer. J Natl Cancer Inst 106: dju051.

World Health Organization (1992) ICD-10: international statistical classification of diseases and related health problems. Tenth Revision. World Health Organization: Geneva, Switzerland.

(c) (2) (2) This work is licensed under the Creative Commons Attribution-Non-Commercial-Share Alike 4.0 International License. To view a copy of this license, visit http:// creativecommons.org/licenses/by-nc-sa/4.0/ 